\title{
Development and evaluation of a duplex TaqMan qPCR assay for detection and quantification of Trypanosoma cruzi infection in domestic and sylvatic reservoir hosts
}

Diana P. Wehrendt ${ }^{1}$, Andrea Gómez-Bravo², Juan C. Ramirez¹, Carolina Cura' ${ }^{1}$, Angélica Pech-May³, Janine M. Ramsey ${ }^{3}$, Marcelo Abril ${ }^{2}$, Felipe Guhl ${ }^{4}$ and Alejandro G. Schijman ${ }^{1 *}$

\begin{abstract}
Background: A question of epidemiological relevance in Chagas disease studies is to understand Trypanosoma cruzi transmission cycles and trace the origins of (re)emerging cases in areas under vector or disease surveillance. Conventional parasitological methods lack sensitivity whereas molecular approaches can fill in this gap, provided that an adequate sample can be collected and processed and a nucleic acid amplification method can be developed and standardized. We developed a duplex qPCR assay for accurate detection and quantification of T. cruzi satellite DNA (satDNA) sequence in samples from domestic and sylvatic mammalian reservoirs. The method incorporates amplification of the gene encoding for the interphotoreceptor retinoid-binding protein (IRBP), highly conserved among mammalian species, as endogenous internal amplification control (elAC), allowing distinction of false negative PCR findings due to inadequate sample conditions, DNA degradation and/or PCR interfering substances.

Results: The novel TaqMan probe and corresponding primers employed in this study improved the analytical sensitivity of the assay to $0.01 \mathrm{par} . e \mathrm{~g} / \mathrm{ml}$, greater than that attained by previous assays for Tc I and Tc IV strains. The assay was tested in 152 specimens, 35 from 15 different wild reservoir species and 117 from 7 domestic reservoir species, captured in endemic regions of Argentina, Colombia and Mexico and thus potentially infected with different parasite discrete typing units. The elACs amplified in all samples from domestic reservoirs from Argentina and Mexico, such as Canis familiaris, Felis catus, Sus scrofa, Ovis aries, Equus caballus, Bos taurus and Capra hircus with quantification cycles (Cq's) between 23 and 25. Additionally, the elACs amplified from samples obtained from wild mammals, such as small rodents Akodon toba, Galea leucoblephara, Rattus rattus, the opossums Didelphis virginiana, D. marsupialis and Marmosa murina, the bats Tadarida brasiliensis, Promops nasutus and Desmodus rotundus, as well as in Conepatus chinga, Lagostomus maximus, Leopardus geoffroyi, Lepus europaeus, Mazama gouazoubira and Lycalopex gymnocercus, rendering Cq's between 24 and 33.
\end{abstract}

Conclusions: This duplex qPCR assay provides an accurate laboratory tool for screening and quantification of T. cruzi infection in a vast repertoire of domestic and wild mammalian reservoir species, contributing to improve molecular epidemiology studies of T. cruzi transmission cycles.

\footnotetext{
*Correspondence: schijman@dna.uba.ar; aleschijman@gmail.com

1 Laboratorio de Biología Molecular de la Enfermedad de Chagas, INGEBI-

CONICET, Buenos Aires, Argentina

Full list of author information is available at the end of the article
} 
Keywords: Trypanosoma cruzi, Chagas disease, Mammalian reservoirs, Molecular epidemiology, Internal amplification standard, Multiplex qPCR, Parasite load

\section{Background}

Chagas disease, a neglected tropical disease caused by the protozoan parasite Trypanosoma cruzi is endemic in Latin America, where it is mainly transmitted by hematophagous insects belonging to the genera Triatoma, Rhodnius, Pastrongylus and Mepraia. Other transmission routes, such as congenital (from mother to child), oral (by consuming contaminated food) and through blood transfusions and organ transplantation, are also important. Approximately seven million people are estimated to suffer from Chagas disease and hundreds of thousands of infected individuals have migrated to non-endemic countries [1].

The natural cycles of transmission involve sylvatic, domestic and peridomestic habitats. Opossums, armadillos and rodents are major sylvatic reservoir hosts, whereas humans, dogs, cats and commensal (synanthropic) rodents are the main hosts in domestic or peridomestic habitats [2-4]. A major question of epidemiological relevance is whether these types of transmission cycles are connected or independent. Characterizing the level of interconnection/ independence of these transmission cycles is paramount to trace the origins of (re)emerging cases in areas under vector or disease surveillance $[5,6]$.

Assessing the infection status of potential mammalian reservoirs is essential. Molecular techniques, such as qPCR have much greater sensitivity than conventional parasitological methods [7-11]. However, the diverse composition of biological samples collected from different mammalian reservoir species may affect amplification accuracy, making it difficult to compare prevalence of infection among different species within a same area under study and/or between different geographical regions. Blood samples may contain substances acting as qPCR inhibitors, leading to false negative results and sub-estimated prevalence rates. The quality of the sample may be altered during transportation from the site of blood collection to the molecular biology laboratory and/or during DNA purification. Accordingly, an accurate method must include an internal amplification control. In this context, we aimed to develop a duplex qPCR assay which would allow for simultaneous amplification of a T. cruzi DNA specific target and an endogenous internal control (eIAC) as amplification standard. The design of novel TaqMan probe and primers targeting a satellite DNA (satDNA) sequence allowed for improved analytical sensitivity, beyond that of other previously developed assays based on the same target $[12,13]$, especially for TcI and TcIV strains [14]. The eIAC was based on a gene fragment encoding the interphotoreceptor retinoid-binding protein (IRBP), which is highly conserved among mammalian species and its usefulness as a DNA integrity control was previously reported in a conventional PCR assay [15]. Once standardized, the duplex assay has been evaluated in a panel of biological samples collected from different sylvatic and domestic mammalian species captured in field studies at endemic areas of Argentina, Colombia and Mexico.

\section{Methods \\ Mammalian reservoir samples \\ Analysis of a standard panel of samples}

A first evaluation of the duplex T. cruzi satDNA/IRBP qPCR assay (index test) was carried out using archival DNA from blood samples of well-characterized domestic and sylvatic mammalian species previously tested using standardized qPCR procedures (comparator test, [13]) in order to estimate their agreement.

\section{Analysis of field samples}

The index method was assayed using DNA extracted from peripheral blood samples preserved in guanidine hydrochloride 6M, EDTA 0.2 M (GE), pH 8.00 (blood:GE proportion of 1:3) and collected from domestic and sylvatic mammalian reservoirs captured in endemic regions from Argentina, Colombia and Mexico.

Argentinean wild and domestic samples were provided by Andrea Gomez-Bravo (Fundación Mundo Sano, Buenos Aires, Argentina) from Añatuya, Santiago del Estero, Argentina. Colombian samples were provided by Felipe Guhl (Universidad de los Andes, Bogotá, Colombia). Mexican samples were collected from mammalian reservoirs captured in an endemic region for Chagas disease in Yucatán, Mexico and kindly provided by Janine M. Ramsey (Centro Regional de Investigación en Salud Pública, Chiapas, Mexico).

\section{DNA extraction methods}

DNA was extracted from $300 \mu \mathrm{l}$ of whole blood/GE samples (blood:GE proportion of 1:3) using phenol-chloroform based purification (for Mexican samples) or the High Pure PCR Template Preparation Kit (Roche Diagnostic Corp., Indiana, USA), following manufacturer instructions (for Argentinean and Colombian samples). 


\section{Design of an endogenous internal amplification standard for duplex qPCR}

A pair of primers and a TaqMan probe complementary to a highly conserved region within the amplified zone of the highly conserved mammalian IRBP gene were designed. Primer IRBP2 Fw was modified with respect to primer IRBP-CF-FWD reported by Ferreira et al. [15] for molecular diagnosis of leishmaniasis. Primer IRBP3Rv and probe IRBPTq were designed from a consensus sequence obtained after the alignment of IRBP sequences, available from 9 domestic and 8 wild mammalian reservoir species on GenBank (Table 1, Fig. 1).

\section{Duplex TaqMan qPCR assay}

The reaction was performed in a final volume of 20 $\mu \mathrm{l}$ with FastStart Universal Probe Master Mix (Roche Diagnostics, Mannheim, Germany) and $5 \mu \mathrm{l}$ of DNA, in a Rotor-Gene 3000 (Corbett Life Science, Cambridge, UK) or an ABI 7500 (Applied Biosystems, Foster City, CA) device. For T. cruzi DNA amplification, new primers Cruzi1c, Cruzi2c [14] and probe Cruzi3 were used to enhance sensitivity with respect to a previous satDNA qPCR [12], in particular for Tc I and Tc IV strains. An internal amplification standard was amplified using primers IRBP Fw and Rv and IRBP probe. Their sequences and final concentrations in the qPCR reaction are given in Table 1. Cycling conditions were an initial step of $10 \mathrm{~min}$ at $95{ }^{\circ} \mathrm{C}$ and 45 cycles at $95{ }^{\circ} \mathrm{C}$ for $15 \mathrm{~s}$ and $56{ }^{\circ} \mathrm{C}$ for 1 min.

\section{Analytical parameters of duplex T. cruzi satDNA/IRBP qPCR assay}

The satDNA single qPCR reaction was inclusive for strains belonging to discrete typing units DTUs TcI to TcVI, as previously reported [14]. To assess analytical sensitivity of the duplex format, blood from noninfected dogs was spiked with cultured epimastigotes of CL Brener and Silvio X10 T. cruzi strains (TcVI and TcI, respectively) to a final concentration of $10^{7}$ parasite equivalents $/ \mathrm{ml}$ (par.eq/ml) and treated with three volumes of guanidine hidrochloride 6 M-EDTA $0.2 \mathrm{M}(\mathrm{pH}$ 8.00) (GE). Next, 10-fold serial dilutions were performed to cover a range between 0.001 to $10^{6} \mathrm{par} . \mathrm{eq} / \mathrm{ml}$. DNA of each dilution was purified and amplified in duplicate by duplex qPCR. Theoretical versus measured Cq values were converted to $\log 10 \mathrm{par} . \mathrm{eq} / \mathrm{ml}$ and plotted for linear regression analysis. Analytical sensitivity was estimated using triplicate dilutions of the above-mentioned spiked samples for both parasites and analytical specificity was

Table 1 Primer and probe sequences and concentrations used in duplex TaqMan qPCR assay for detection of T. cruzi DNA in mammalian reservoir species

\begin{tabular}{|c|c|c|c|c|c|}
\hline Gene target & Primer/probe name & Primer/probe sequence $\left(5^{\prime}-3^{\prime}\right)$ & $\begin{array}{l}\text { Reaction } \\
\text { concentration }(\mu \mathrm{M})\end{array}$ & $\begin{array}{l}\text { Amplicon } \\
\text { size (bp) }\end{array}$ & Source \\
\hline \multirow{3}{*}{$\begin{array}{l}\text { Satellite repeat unit } \\
\text { from T. cruzi genome }\end{array}$} & Primer Cruzi 1c & TGAATGGYGGGAGTCAGAG & 0.75 & \multirow[t]{3}{*}{98} & \multirow[t]{3}{*}{ Ramírez et al. [14] } \\
\hline & Primer Cruzi 2c & ATTCCTCCAAGMAGCGGAT & 0.75 & & \\
\hline & Probe Cruzi 3 & FAM-CACACACTGGACACCAA-NFQ-MGB & 0.05 & & \\
\hline \multirow{3}{*}{$\begin{array}{l}\text { IRBP gene from mam- } \\
\text { malian genome }\end{array}$} & Primer IRBP2 FW & CCAAYACVACCACTGAGATCTG & 0.60 & \multirow[t]{3}{*}{140} & \multirow[t]{3}{*}{ Present study } \\
\hline & Primer IRBP3 RV & GCGCATCTGYTTGAGGATGTARG & 0.60 & & \\
\hline & Probe IRBP Tq & HEX-TGGTGGTCCTCACCAG-NFQ-MGB & 0.05 & & \\
\hline
\end{tabular}

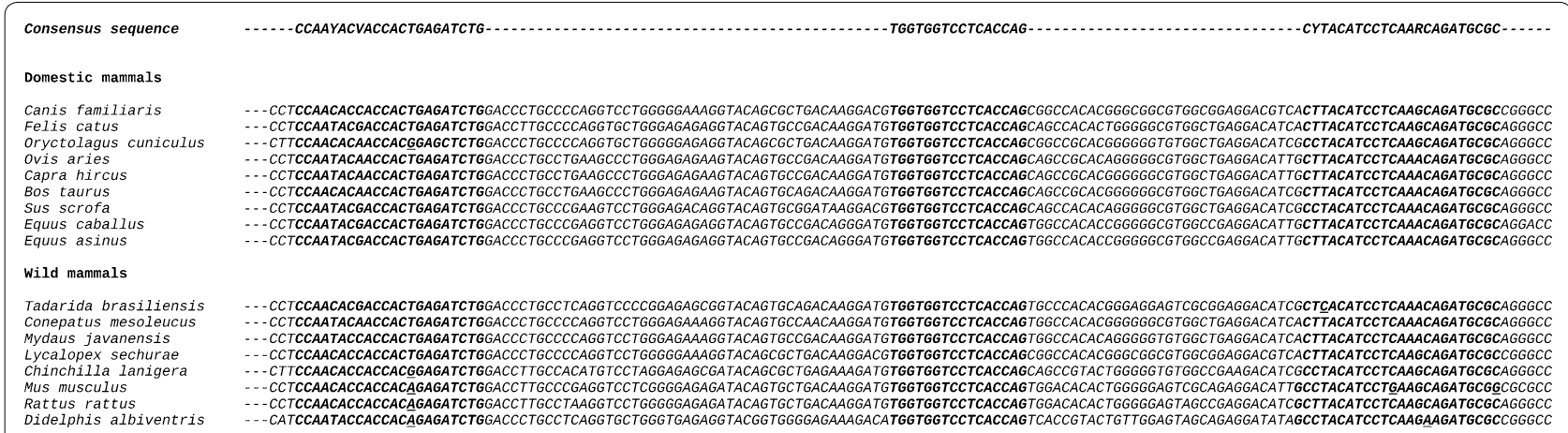

Fig. 1 IRBP sequence alignment for different wild and domestic reservoir species. Primer and probe annealing sequences are highlighted in bold letters. Nucleotides that differ from the primer or probe sequences are underlined 
estimated using DNA from T. rangeli, Leishmania major, L. donovani and L. amazonensis.

\section{Quality controls of the duplex $T$. cruzi satDNA/IRBP qPCR assay}

Each DNA extraction round included one blood sample from a seronegative dog as a negative extraction control. Each amplification round included two positive DNA controls containing 1 par.eq $/ \mathrm{ml}$ and 100 par.eq $/ \mathrm{ml}$ of CL Brener spiked dog samples and one non-template control.

The satDNA/IRBP qPCR results were considered as valid when the Cq of IRBP was within the expected range according to the criteria of Tukey: Cq's.75th percentile $+1.5 \times$ interquartile distance of median $\mathrm{Cq}$, which would indicate inhibition or material loss in samples from the same experiment with $n>10$ [16].

\section{Trypanosoma cruzi DNA quantification of satDNA/IRBP qPCR positive samples}

A panel of 22 satDNA/IRBP qPCR-positive samples was quantified for estimation of parasite load. For this, a standard quantification curve was constructed. Given that satDNA qPCR positive samples were genotyped as TcI $[17,18]$, DNA was obtained from non-infected dog blood spiked with $10^{7}$ par.eq $/ \mathrm{ml}$ of Silvio X10 clone (TcI) cultured parasites, and serially diluted in DNA obtained from blood collected from non-infected dogs aiming to cover a range of standards containing $10^{-1}$ to $10^{5}$ par.eq/ $\mathrm{ml}$.

\section{Data analysis}

To compare the agreement between the index duplex qPCR assay with comparator standardized qPCR procedures in a panel of characterized samples, inter-observer kappa coefficients were calculated using GraphPad Software online statistical calculators (http://www.graphpad. com/quickcalcs/kappa1.cfm). Kappa values $<0.01$ indicate no agreement, those between 0.1 and 0.4 indicate weak agreement, those between 0.41 and 0.60 indicate clear agreement, those between 0.61 and 0.80 indicate strong agreement, and those between 0.81 and 1.00 indicate nearly perfect agreement.

\section{Results}

Design and analytical performance of duplex T.cruzi satDNA/IRBP qPCR assay

IRBP primer and probe sequences were designed from a consensus IRBP sequence obtained after alignment of orthologous sequences from different mammalian species, available in the GenBank database (Table 1, Fig. 1). The reportable range of $T$. cruzi satDNA/IRBP qPCR assay was assessed in single and duplex formats
(Additional file 1: Figure S1). No significant differences between single T. cruzi satDNA qPCR and duplex T. cruzi satDNA /IRBP qPCR were observed when comparing the Cq values obtained for different $T$. cruzi DNA concentrations ranging between 10 and $10^{5} \mathrm{par} . e \mathrm{q} / \mathrm{ml}$ (Additional file 1: Figure S1).

The duplex T. cruzi sat DNA/IRBP qPCR analytical sensitivity was evaluated in dog blood samples spiked with cultured parasites from the Silvio X10 (TcI) and CL Brener (TcVI) stocks. The reportable range was from 0.1 to $10^{5}$ par.eq. $/ \mathrm{ml}$ and from 1 to $10^{4}$ par.eq. $/ \mathrm{ml}$ for $\mathrm{CL}$ Brener and Silvio X10 stocks, respectively. Analytical sensitivities were 0.01 par.eq $/ \mathrm{ml}$ for both $T$. cruzi stocks.

The assay amplified exclusively T. cruzi DNA samples; in contrast, it did not amplify DNA from different Leishmania species and T. rangeli (Table 2). Moreover, we compared the agreement between the duplex T. cruzi sat DNA/IRBP qPCR assay with previously reported PCR procedures in a panel of well-characterized blood samples from domestic and sylvatic mammal reservoirs (Table 3). An almost perfect agreement (\% of agreement: 97.83\%; Cohen's k: 0.95) was obtained.

\section{Evaluation of blood samples from wild and domestic reservoirs}

Blood sample panels from different mammalian species captured in three endemic regions for Chagas disease (Santiago del Estero, Argentina; Maní, Colombia; and

Table 2 Analytical parameters of the duplex T.cruzi satDNA/IRBP qPCR assay

\begin{tabular}{ll}
\hline Analytical parameter & satDNA/IRBP qPCR \\
\hline Analytical sensitivity, par.eq./ml & \\
TCl (Silvio X10) & 0.01 \\
TCVI (CL Brener) & 0.01 \\
Inclusivity (fg/ $\mu$ ) & \\
TCI (Silvio X10) & 0.25 \\
TC II (Y) & 0.125 \\
TC III (M5631 cl5) & 0.0625 \\
TC IV (4167) & 0.0625 \\
TC V (MnCl2) & 0.0625 \\
TC VI (CL Brener) & 0.0625 \\
Exclusivity (non detectable qPCR) pg/ $\mu \mathrm{l}$ & \\
T. rangeli & 100 \\
L. major & 1000 \\
L. donovani & 1000 \\
L. amazonensis & 100 \\
Reportable range & \\
Cl Brener & $0.1-10^{5} \mathrm{par} . e q / \mathrm{ml} ;$ \\
Silvio X10 & $y=-2.48 \mathrm{X}+22.69 ; R^{2}=0.99$ \\
& $1-10^{4} \mathrm{par} . e q / \mathrm{ml} ;$ \\
\hline
\end{tabular}


Table 3 Comparison of T. cruzi DNA detection by means of $T$. cruzi satDNA/IRBP qPCR assay (index test) and standardized qPCR (comparator test)

\begin{tabular}{llll}
\hline Panel of well-characterized samples & $n$ & \multicolumn{2}{l}{ Index test } \\
\cline { 4 - 4 } & & Positive & Negative \\
\hline Comparator qPCR test-positive & & & \\
Canis familiaris & 5 & 5 & 0 \\
Felis catus & 3 & 3 & 0 \\
Ovis aries & 6 & 6 & 0 \\
Didelphis sp. & 16 & 16 & 0 \\
Total & & & \\
Comparator qPCR test-negative & 9 & 0 & 9 \\
Canis familiaris & 1 & 0 & 1 \\
Felis catus & 3 & 1 & 2 \\
Ovis aries & 9 & 0 & 9 \\
Capra hircus & 6 & 0 & 6 \\
Promops nasutus & 1 & 0 & 1 \\
Conepatus chinga & 1 & 0 & 1 \\
Lagostomus maximus & 30 & 1 & 29 \\
Total & &
\end{tabular}

Note: Comparator qPCR test was reported in Ramirez et al. [13]

Yucatán, México) were tested for simultaneous detection of T. cruzi infection and IRBP amplification (Table 4).

The eIAC amplified in all samples from domestic reservoirs from Argentina and Mexico, such as Canis familiaris, Felis catus, Sus scrofa, Ovis aries, Equus caballus, Bos taurus and Capra hircus with Cq's between 23 and 25. It also amplified samples from wild mammals from Argentina, Colombia and Mexico, such as small rodents Akodon toba, Galea leucoblephara, Rattus rattus, the opossums Didelphis virginiana, D. marsupialis and Marmosa murina, the bats, Tadarida brasiliensis, Promops nasutus and Desmodus rotundus, as well as in Conepatus chinga (skunk), Lagostomus maximus (viscacha), Leopardus geoffroyi (wildcat), Lepus europaeus (hare), Mazama gouazoubira (brown brocket deer) and Lycalopex gymnocercus (Pampas fox) rendering Cq's between 24 and 33 (Table 4). The Tukey's criterion [16] was used to detect samples with outlier Cq values for the eIAC, which would indicate PCR inhibition or material loss in samples from the same experiment with $n>10$. Only one sample of Desmodus rotundus was considered invalid.

Samples from Colombian Didelphis marsupials, Marmosa murina, Mexican dogs, cats and sheep that showed amplification of T. cruzi satDNA were considered positive (Table 4, [14]).

\section{Quantification of parasite load}

TaqMan qPCR allows for quantification of parasitic burden in infected samples. Parasite loads were quantitated in infected sheep, dog and cat samples, as well as in Didelphis marsupialis and Marmosa murina $(n=22)$ (Fig. 2, Table 5). Except for both Ovis aries specimens, individuals from the other species presented heterogeneity in their parasite loads, ranging from 0.14 to $4.0210^{2}$ par.eq $/ \mathrm{ml}$.

\section{Discussion}

Trypanosoma cruzi transmission cycles in sylvatic and domestic mammals have been studied in different ecoepidemiological settings in endemic regions [5]. Initially, microscopic analysis, blood culture or xenodiagnosis were used for detection and isolation of T. cruzi strains from mammalian reservoirs $[19,20]$. Later, studies developed in-house conventional amplification procedures for direct detection and genotyping of T. cruzi in domestic and wildlife reservoirs $[6-9,11,21,22]$ whereas in dogs qPCR assays were carried out [23, 24]. However, methods lacking internal amplification controls could not discriminate between absence of infection and inadequate samples. Here, we have developed a TaqMan-based duplex qPCR procedure useful for detection and quantification of parasite loads in biological samples from wild and domestic mammalian reservoirs, coupled with an IRBPDNA-based internal amplification standard. This enables a distinction between true negative samples and false negative samples due to the presence of PCR interfering substances and/or degradation of DNA.

The assay was evaluated using 35 blood samples from 15 different wild reservoir species and 117 samples from 7 domestic mammalian species. The IRBP-DNAbased integrity control performed adequately in all above mentioned specimens except in one DNA sample from Desmodus rotundus. The IRBP Cq-values were variable in different species, in particular in wild reservoirs, which may arise from different concentrations of nucleated cells in the blood of the different species $[25,26]$ and/or a different yield in blood-based DNA. In the case of column-based DNA extraction procedures, the pigs and wildcats presented the lowest IRBP Cq-values (22.72 and 22.71, respectively) whereas the bat (Promops nasutus) showed the highest Cq-values (32.86). Nevertheless, in some cases, samples of the same species extracted using different DNA purification methods yielded different Cq-values for IRBPDNA. In particular, phenol-chloroform-extracted DNA samples from Mexico yielded higher between-sample mean Cq- and SD-values than those obtained using column-based DNA extraction (Table 4). Previous comparison of DNA extraction methods from blood samples showed that those based in organic solvents rendered a higher degree of PCR inhibition [27, 28]. Thus, in comparative studies of parasitic burden among 
Table 4 IRBP (elAC) gene amplification in duplex satDNA/IRBP qPCR assay for T.cruzi DNA detection in samples from reservoir species

\begin{tabular}{|c|c|c|c|c|c|}
\hline & \multirow[t]{3}{*}{$n$} & \multicolumn{4}{|c|}{ satDNA/IRBP qPCR } \\
\hline & & \multicolumn{3}{|l|}{ IRBP control } & \multirow{2}{*}{$\begin{array}{l}\text { Tcruzi } \\
\text { positive/ } \\
\text { total }\end{array}$} \\
\hline & & Valid samples & Mean Cq & SD & \\
\hline \multicolumn{6}{|l|}{ Wild reservoirs $(n=35)$} \\
\hline \multicolumn{6}{|l|}{ Small rodents } \\
\hline Akodon toba, Argentina & 5 & 5 & 26.29 & 2.22 & $0 / 5$ \\
\hline Galea leucoblephara, Argentina & 1 & 1 & 26.88 & nd & $0 / 1$ \\
\hline Rattus rattus, Argentina & 1 & 1 & 24.72 & nd & $0 / 1$ \\
\hline \multicolumn{6}{|l|}{ Marsupials } \\
\hline Didelphis virginiana, México & 4 & 4 & 24.29 & 1.27 & $0 / 4$ \\
\hline Didelphis marsupialis, Colombia & 3 & 3 & 26.28 & 0.27 & $3 / 3$ \\
\hline Marmosa murina, Colombia & 3 & 3 & 29.73 & 4.91 & $3 / 3$ \\
\hline \multicolumn{6}{|l|}{ Bats } \\
\hline Tadarida brasiliensis, Argentina & 1 & 1 & 24.48 & nd & $0 / 1$ \\
\hline Promops nasutus, Argentina & 4 & 4 & 33.60 & 1.97 & $0 / 4$ \\
\hline Desmodus rotundus (vampire), Argentina & $2^{\mathrm{b}}$ & 1 & 27.90 & nd & $0 / 1$ \\
\hline \multicolumn{6}{|l|}{ Other mammals } \\
\hline Conepatus chinga (skunk), Argentina & 3 & 3 & 24.86 & 1.65 & $0 / 3$ \\
\hline Lagostomus maximus (viscacha), Argentina & 3 & 3 & 28.38 & 0.20 & $0 / 3$ \\
\hline Leopardus geoffroyi (wildcat), Argentina & 1 & 1 & 22.71 & nd & $0 / 1$ \\
\hline Lepus europaeus (hare), Argentina & 1 & 1 & 27.88 & nd & $0 / 1$ \\
\hline Mazama gouazoubira (brown brocket deer), Argentina & 1 & 1 & 26.78 & nd & $0 / 1$ \\
\hline Lycalopex gymnocercus (Pampas fox), Argentina & 2 & 2 & 25.08 & 0.60 & $0 / 2$ \\
\hline \multicolumn{6}{|l|}{ Domestic reservoirs $(n=117)$} \\
\hline Bos taurus (cow), Argentina & 12 & 12 & 24.84 & 0.31 & $0 / 12$ \\
\hline Canis lupus familiaris (dog), Argentina & 27 & 27 & 24.52 & 1.10 & $0 / 27$ \\
\hline Canis lupus familiaris (dog), México a & 4 & 4 & 28.85 & 4.50 & $4 / 4$ \\
\hline Capra hircus (goat), Argentina & 24 & 24 & 23.75 & 1.13 & $0 / 24$ \\
\hline Equus caballus (horse), Argentina & 2 & 2 & 23.40 & 0.49 & $0 / 2$ \\
\hline Felis catus (cat), Argentina & 4 & 4 & 26.21 & 0.37 & $0 / 4$ \\
\hline Felis catus (cat), México & 10 & 10 & 26.45 & 0.61 & $10 / 10$ \\
\hline Ovis aries (sheep), Argentina & 29 & 29 & 25.16 & 0.92 & $0 / 29$ \\
\hline Ovis aries (sheep), México ${ }^{a}$ & 2 & 2 & 32.67 & 1.51 & $2 / 2$ \\
\hline Sus scrofa domesticus (pig), Argentina & 3 & 3 & 22.72 & 0.98 & $0 / 3$ \\
\hline
\end{tabular}

a Phenol chloroform DNA extraction

b One sample was IRBP negative

Note: IRBP amplification and detection of T.cruzi positive cases are shown

Abbreviations: SD, standard deviation; Cq, quantification cycle; nd, not determined

individuals from the same species and/or among other reservoir species, the same DNA extraction procedure should be used and the acceptable range of IRBP Cqvalues should be estimated for each round and method of DNA extraction in order to detect outlier Cq-values that allow distinction of false negative samples [16]. We have explored the capacity of the IRBP internal control to detect DNA degradation by performing the following experiments: incubation of DNA samples for 48 hours at room temperature and exposition of DNA samples to UV light. In both cases the Cq-values of IRBP increased compared to outlier values (unpublished results). 


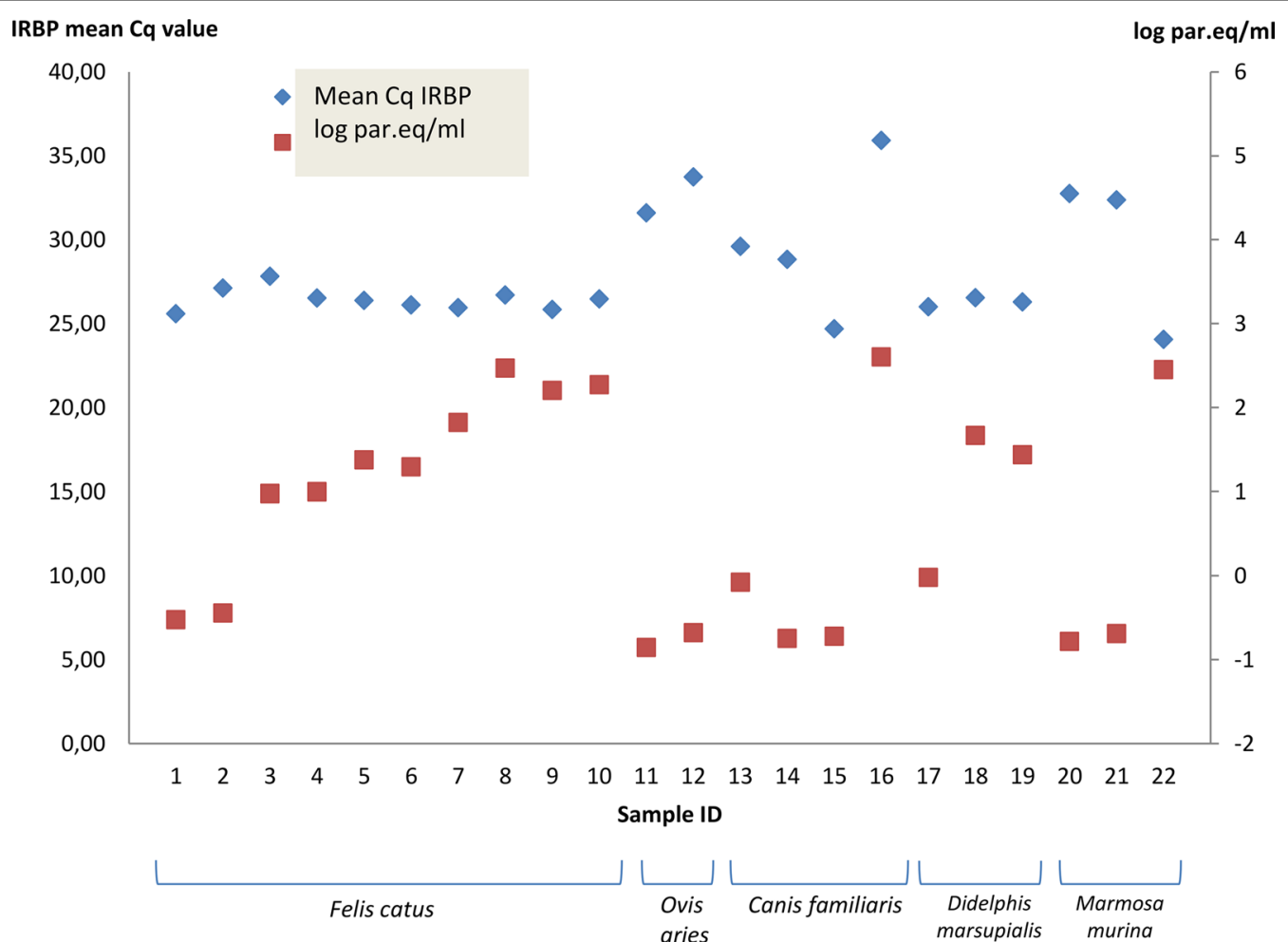

Fig. 2 Quantification of parasite loads by means of duplex T. cruzi satDNA/IRBP qPCR in infected specimens. Quantification is expressed in parasite equivalents $/ \mathrm{ml}$ of blood

On the other hand, high parasite loads may inhibit amplification of IRBP. This will not be a problem for qualitative detection of T. cruzi infection, but if accurate parasite load quantifications are required, it is recommended to dilute the clinical sample and repeat the qPCR assay to achieve IRBP Cq-values within the acceptable range.

The high analytical sensitivity for satDNA amplification for both CL Brener and Silvio X10 stocks obtained with our assay had not been previously achieved, especially for TcI and TcIV strains [12, 13]. Probably, the exhaustive alignment for satDNA sequences performed in this study, including a higher number of strains for each T. cruzi stock, contributed in this regard [14]. Indeed, to our knowledge, this is the first time that this set of
satDNA-based PCR primers and probe have been used in biological specimens.

\section{Conclusions}

Our results indicate this novel assay is useful for T. cruzi infection screening in samples from different mammalian species, either in prospective studies or employing archival DNA. Sample quality can be inferred by means of eIAC amplification. Moreover, the quantification of parasite load may be indicative of the severity and the stage of infection in these reservoir species and their "transmission potential" in their habitats, thus contributing to epidemiological knowledge of factors involved in T. cruzi transmission cycles. 
Table 5 Parasite loads in satDNA/IRBP qPCR-positive samples from mammalian reservoir hosts

\begin{tabular}{|c|c|c|c|c|c|c|}
\hline \multirow[t]{2}{*}{ Sample ID } & \multirow[t]{2}{*}{ Mammalian species } & \multicolumn{4}{|c|}{ Duplex SatDNA/IRBP qPCR } & \multirow[t]{2}{*}{ DTU } \\
\hline & & Mean Cq IRBP & Mean Cq cruzi & par.eq/ml & log par.eq/ml & \\
\hline 1 & Felis catus & 25.59 & 28.70 & 0.30 & -0.522878745 & $\mathrm{TCl}$ \\
\hline 2 & Felis catus & 27.13 & 28.52 & 0.36 & -0.443697499 & $\mathrm{Tcl}$ \\
\hline 3 & Felis catus & 27.82 & 24.78 & 9.49 & 0.977266212 & $\mathrm{Tcl}$ \\
\hline 4 & Felis catus & 26.53 & 24.73 & 9.94 & 0.997386384 & $\mathrm{Tcl}$ \\
\hline 5 & Felis catus & 26.39 & 23.75 & 23.72 & 1.375114685 & $\mathrm{Tcl}$ \\
\hline 6 & Felis catus & 26.11 & 23.96 & 19.67 & 1.29380436 & $\mathrm{Tcl}$ \\
\hline 7 & Felis catus & 25.96 & 25.58 & 66.40 & 1.822168079 & $\mathrm{Tcl}$ \\
\hline 8 & Felis catus & 26.70 & 20.89 & 296.45 & 2.471951455 & $\mathrm{Tcl}$ \\
\hline 9 & Felis catus & 25.84 & 21.58 & 160.17 & 2.204581176 & $\mathrm{Tcl}$ \\
\hline 10 & Felis catus & 26.48 & 21.40 & 187.50 & 2.273001272 & $\mathrm{Tcl}$ \\
\hline 11 & 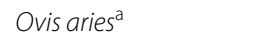 & 31.61 & 29.45 & 0.14 & -0.853871964 & $\mathrm{Tcl} / \mathrm{TcV}$ \\
\hline 12 & Ovis aries ${ }^{\mathrm{a}}$ & 33.74 & 29.13 & 0.21 & -0.677780705 & $\mathrm{Tcl} / \mathrm{TCV}$ \\
\hline 13 & Canis familiaris $^{\mathrm{a}}$ & 29.60 & 27.47 & 0.84 & -0.075720714 & $\mathrm{TcVl}$ \\
\hline 14 & Canis familiaris $^{\mathrm{a}}$ & 28.83 & 29.31 & 0.18 & -0.744727495 & $\mathrm{Tcl} / \mathrm{TCV}$ \\
\hline 15 & Canis familiaris $^{\mathrm{a}}$ & 24.69 & 29.27 & 0.19 & -0.721246399 & $\mathrm{Tcl} / \mathrm{TcV}$ \\
\hline 16 & Canis familiaris & 35.92 & 18.23 & 402.73 & 2.60500859 & $\mathrm{Tcl}$ \\
\hline 17 & Didelphis marsupialis & 26.01 & 26.80 & 0.96 & -0.017728767 & nd \\
\hline 18 & Didelphis marsupialis & 26.54 & 21.29 & 46.41 & 1.666564777 & nd \\
\hline 19 & Didelphis marsupialis & 26.30 & 22.04 & 27.39 & 1.437592032 & nd \\
\hline 20 & Marmosa murina & 32.76 & 29.28 & 0.17 & -0.782516056 & nd \\
\hline 21 & Marmosa murina & 32.37 & 29.17 & 0.21 & -0.688246139 & nd \\
\hline 22 & Marmosa murina & 24.07 & 18.72 & 284.38 & 2.453891414 & nd \\
\hline
\end{tabular}

a DNA extracted with phenol-chloroform

Abbreviation: nd, not determined

\section{Supplementary information}

Supplementary information accompanies this paper at https://doi. org/10.1186/s13071-019-3817-9.

Additional file 1: Figure S1. Comparison of single and duplex T. cruzi satDNA qPCR reportable ranges for detection and quantification of T. cruzi DNA.

\section{Abbreviations}

qPCR: real time polymerase chain reaction; satDNA: satellite DNA; IRBP. interphotoreceptor retinoid-binding protein; elAC: endogenous internal amplification control; Cq: quantification cycle; par.eq/ml: parasite equivalents per milliliter; UV light: ultraviolet light; SD: standard deviation; DTU: discrete typing unit; GE: guanidine hydrochloride/EDTA.

\section{Acknowledgments}

We are grateful to María de los Angeles Curto for culturing parasites to construct the quantification curve and to Paula Beati for her assistance in editing figures.

\section{Authors' contributions}

DW, JCR and AGS conceived and designed the qPCR assay. DW performed DNA extraction and qPCR experiments. AGB and CC collected biological samples from Argentina, APM and JR collected samples from Mexico and FG from Colombia. CC, APM and FG performed identification of DTUs. DW and AGS wrote the first version of the manuscript and all authors revised it. AGS, MA and FG conceived the study. AGS and MA provided financial support. AGS supervised molecular diagnosis related work. All authors read and approved the final manuscript.

\section{Funding}

This study was possible thanks to the financial support from ANPCyT through PICT 2014-0274 to AGS and funds from the Fundación Mundo Sano, Argentina.

\section{Availability of data and materials}

Data supporting the conclusions of this article are included within the article and its additional file. All raw data are available upon request to the corresponding authors or at http://ingebi-conicet.gov.ar/biologia-molecularde-la-enfermedad-de-chagas/.

\section{Ethics approval and consent to participate}

All mammalian samples were collected according to the national or provincial guidelines of each State.

\section{Consent for publication}

Not applicable

\section{Competing interests}

The authors declare that they have no competing interests.

\section{Author details}

${ }^{1}$ Laboratorio de Biología Molecular de la Enfermedad de Chagas, INGEBICONICET, Buenos Aires, Argentina. ${ }^{2}$ Fundación Mundo Sano, Buenos Aires, Argentina. ${ }^{3}$ Centro Regional de Investigación en Salud Pública, Instituto Nacional de Salud Pública, Chiapas, México. ${ }^{4}$ Universidad de los Andes, Bogotá, Colombia. 
Received: 17 May 2019 Accepted: 20 November 2019

Published online: 29 November 2019

\section{References}

1. WHO. Chagas disease in Latin America: an epidemiological update based on 2010 estimates. Wkly Epidemiol Rec. 2010;2015(90):33-44.

2. Jansen AM, Xavier SC, Roque AL. The multiple and complex and changeable scenarios of the Trypanosoma cruzi transmission cycle in the sylvatic environment. Acta Trop. 2015;151:1-15.

3. Minter DM. Epidemiology of Chagas' disease. Trans R Soc Trop Med Hyg. 1976;70:124.

4. Noireau F, Diosque P, Jansen AM. Trypanosoma cruzi: adaptation to its vectors and its hosts. Vet Res. 2009;40:26.

5. Miles MA, Llewellyn MS, Lewis MD, Yeo M, Baleela R, Fitzpatrick S, et al. The molecular epidemiology and phylogeography of Trypanosoma cruzi and parallel research on Leishmania: looking back and to the future. Parasitology. 2009;136:1509-28.

6. Argibay HD, Orozco MM, Cardinal MV, Rinas MA, Arnaiz M, Mena Segura C, et al. First finding of Trypanosoma cruzi II in vampire bats from a district free of domestic vector-borne transmission in northeastern Argentina. Parasitology. 2016;143:1358-68.

7. Orozco MM, Enriquez GF, Alvarado-Otegui JA, Cardinal MV, Schijman AG, Kitron U, et al. New sylvatic hosts of Trypanosoma cruzi and their reservoir competence in the humid Chaco of Argentina: a longitudinal study. Am J Trop Med Hyg. 2013;88:872-82.

8. Enriquez GF, Cardinal MV, Orozco MM, Schijman AG, Gürtler RE. Detection of Trypanosoma cruzi infection in naturally infected dogs and cats using serological, parasitological and molecular methods. Acta Trop. 2013;126:211-7

9. Monje-Rumi MM, Brandán CP, Ragone PG, Tomasini N, Lauthier JJ, Alberti D'Amato AM, et al. Trypanosoma cruzi diversity in the Gran Chaco: mixed infections and differential host distribution of TcV and TcVI. Infect Genet Evol. 2015;29:53-9.

10. Falla A, Herrera C, Fajardo A, Montilla M, Vallejo GA, Guhl F. Haplotype identification within Trypanosoma cruzi I in Colombian isolates from several reservoirs, vectors and humans. Acta Trop. 2009;110:15-21.

11. Cardinal MV, Lauricella MA, Ceballos LA, Lanati L, Marcet PL, Levin MJ, et al. Molecular epidemiology of domestic and sylvatic Trypanosoma cruzi infection in rural northwestern Argentina. Int J Parasitol. 2008;38:1533-43.

12. Duffy T, Cura Cl, Ramirez JC, Abate T, Cayo NM, Parrado R, et al. Analytical performance of a multiplex real-time PCR assay using TaqMan probes for quantification of Trypanosoma cruzi satellite DNA in blood samples. PLoS Negl Trop Dis. 2013;7:e2000.

13. Ramírez JC, Cura $\mathrm{Cl}$, da Cruz Moreira O, Lages-Silva E, Juiz N, Velázquez E, et al. Analytical validation of quantitative real-time PCR methods for quantification of Trypanosoma cruzi DNA in blood samples from Chagas disease patients. J Mol Diagn. 2015;17:605-15.

14. Ramírez JC, Torres C, Curto MLA, Schijman AG. New insights into Trypanosoma cruzi evolution, genotyping and molecular diagnostics from satellite DNA sequence analysis. PLoS Negl Trop Dis. 2017;11:e0006139.
15. Ferreira EC, Gontijo CM, Cruz I, Melo MN, Silva AM. Alternative PCR protocol using a single primer set for assessing DNA quality in several tissues from a large variety of mammalian species living in areas endemic for leishmaniasis. Mem Inst Oswaldo Cruz. 2010;105:895-8.

16. Burns MJ, Nixon GJ, Foy CA, Harris N. Standardisation of data from realtime quantitative PCR methods - evaluation of outliers and comparison of calibration curves. BMC Biotechnol. 2005;5:31.

17. Cura Cl, Duffy T, Lucero RH, Bisio M, Péneau J, Jimenez-Coello M, et al. Multiplex real-time PCR assay using TaqMan probes for the identification of Trypanosoma cruzi DTUs in biological and clinical samples. PLoS Negl Trop Dis. 2015;9:e0003765.

18. López-Cancino SA, Tun-Ku E, De la Cruz-Felix HK, Ibarra-Cerdeña CN, Izeta-Alberdi A, Pech-May A, et al. Landscape ecology of Trypanosoma cruzi in the southern Yucatan Peninsula. Acta Trop. 2015;151:58-72.

19. Yaeger RG. The prevalence of Trypanosoma cruzi infection in armadillos collected at a site near New Orleans, Louisiana. Am J Trop Med Hyg. 1988;38:323-6

20. Barr SC, Brown CC, Dennis VA, Klei TR. The lesions and prevalence of Trypanosoma cruzi in opossums and armadillos from southern Louisiana. J Parasitol. 1991:77:624-7.

21. Martínez MF, Kowalewski MM, Salomón OD, Schijman AG. Molecular characterization of trypanosomatid infections in wild howler monkeys (Alouatta caraya) in northeastern Argentina. Int J Parasitol Parasites Wildl. 2016;5:198-206.

22. Curtis-Robles R, Lewis BC, Hamer SA. High Trypanosoma cruzi infection prevalence associated with minimal cardiac pathology among wild carnivores in central Texas. Int J Parasitol Parasites Wildl. 2016:5:117-23.

23. Jaimes-Dueñez J, Triana-Chávez O, Cantillo-Barraza O, Hernández C, Ramírez JD, Góngora-Orjuela A. Molecular and serological detection of Trypanosoma cruzi in dogs (Canis lupus familiaris) suggests potential transmission risk in areas of recent acute Chagas disease outbreaks in Colombia. Prev Vet Med. 2017;141:1-6.

24. Tahir D, Davoust B, Heu K, Lamour T, Demar M, Marié JL, et al. Molecular and serological investigation of Trypanosoma cruzi infection in dogs in French Guiana. Vet Parasitol Reg Stud Reports. 2017;12:106-9.

25. Weiss DJ, Wardrop KJ. Schalm's Veterinary hematology. 6th ed. Hoboken: Wiley-Blackwell; 2010.

26. Latimer KS. Duncan and Prasse's veterinary laboratory medicine: clinical pathology. 5th ed. Hoboken: Wiley-Blackwell; 2011.

27. Marcet PL, Duffy T, Cardinal MV, Burgos JM, Lauricella MA, Levin MJ, et al. PCR-based screening and lineage identification of Trypanosoma cruzi directly from faecal samples of triatomine bugs from northwestern Argentina. Parasitology. 2006;132:57-65.

28. Duffy T, Bisio M, Altcheh J, Burgos JM, Diez M, Levin MJ, et al. Accurate real-time PCR strategy for monitoring bloodstream parasitic loads in Chagas disease patients. PLoS Negl Trop Dis. 2009;3:e41.

\section{Publisher's Note}

Springer Nature remains neutral with regard to jurisdictional claims in published maps and institutional affiliations.

\footnotetext{
Ready to submit your research? Choose BMC and benefit from:

- fast, convenient online submission

- thorough peer review by experienced researchers in your field

- rapid publication on acceptance

- support for research data, including large and complex data types

- gold Open Access which fosters wider collaboration and increased citations

- maximum visibility for your research: over 100M website views per year
}

At BMC, research is always in progress.

Learn more biomedcentral.com/submissions 